SANDIA REPORT

SAND95-2120 - UC-410

Unlimited Release

Printed February 1997

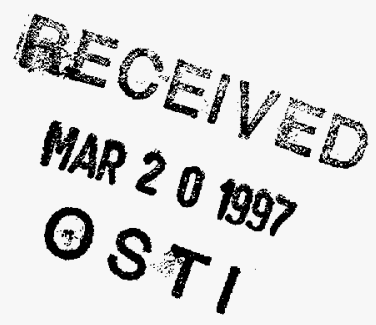

\title{
A Passive Micromachined Device for Alignment of Arrays of Single-mode Fibers for Hermetic Photonic Packaging - The CLASP Concept
}

Approved for public release; distribution is unlimitod

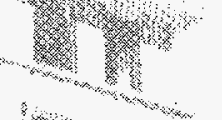

\section{in Sandia National Laboratories}
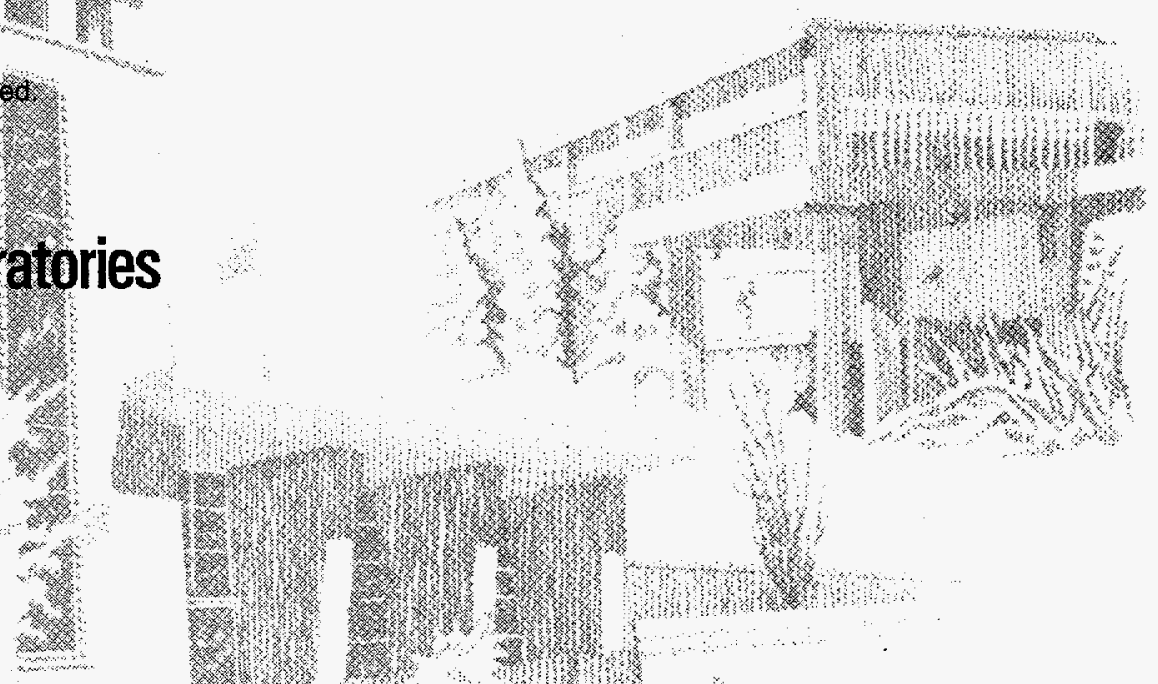

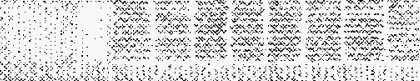

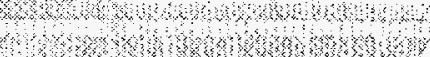

(x)

3.

SF29000(8-81) 
Issued by Sandia National Laboratories, operated for the United States Department of Energy by Sandia Corporation.

NOTICE: This report was prepared as an account of work sponsored by an agency of the United States Government. Neither the United States Government nor any agency thereof, nor any of their employees, nor any of their contractors, subcontractors, or their employees, makes any warranty, express or implied, or assumes any legal liability or responsibility for the accuracy, completeness, or usefulness of any information, apparatus, product, or process disclosed, or represents that its use would not infringe privately owned rights. Reference herein to any specific commercial product, process, or service by trade name, trademark, manufacturer, or atherwise, does not necessarily constitute or imply its endorsement, recommendation, or favoring by the United States Government, any agency thereof, or any of their contractors or subcontractors. The views and opinions expressed herein do not necessarily state or reflect those of the United States Government, any agency thereof, or any of their contractors.

Printed in the United States of America. This report has been reproduced directly from the best available copy.

Available to DOE and DOE contractors from

Office of Scientific and Technical Information

P.O. Box 62

Oak Ridge, TN 37831

Prices available from (615) 576-8401, FTS 626-8401

Available to the public from

National Technical Information Service

U.S. Department of Commerce

5285 Port Royal Rd

Springfield, VA 22161

NTIS price codes

Printed copy: A03

Microfiche copy: A01 


\section{DISCLAIMER}

Portions of this document may be illegible in electronic image products. Images are produced from the best available original document. 
SAND95-2120

Unlimited Release

Distribution

Printed February 1997

Category UC-410

\title{
A Passive Micromachined Device for Alignment of Arrays of Single-mode Fibers for Hermetic Photonic Packaging - The CLASP Concept
}

\author{
P. K. Seigal \\ Advanced Packaging Department \\ S. H. Kravitz, J. C. Word*, T. M. Bauer \\ Advanced Compound Semiconductor Technologies Department \\ M. G. Armendariz \\ Advanced Devices and Applications Department \\ Sandia National Laboratories \\ P.O. Box 5800 \\ Albuquerque, New Mexico, 87185-0603 \\ *Presently located at: \\ Microchip Inc. \\ Tempe, Arizona
}

\begin{abstract}
A micro-machined fiber alignment device, called CLASP (Capture and Locking Alignment Spring Positioner) has been fabricated. It uses a nickel leaf spring to passively capture vertical arrays of single-mode fibers with $\sim 2 \mu \mathrm{m}$ accuracy.
\end{abstract}




\section{A Passive Micromachined Device for Alignment of Arrays of Single-mode Fibers for Hermetic Photonic Packaging - The CLASP Concept}

\section{Introduction}

Alignment of single-mode optical fibers to photonic devices has proven to be the most expensive single item in the cost of packaged photonic devices. The difficulty is compounded if an array of fibers is intended for alignment, and is further compounded if the desired packaged device is to be hermetic.

In a previous paper [1], a method was reported that coupled light in or out of waveguide devices through second-order gratings to binary optics on the bottom of the package lid. On the outside of the package lid was an array of fibers aligned to the binary optics. The binary optics were focused on the front surface of the fibers. The method of capturing and holding the array of fibers was not specified. In this paper, we are proposing a micromachine as the method of capture. (Fig. 1)

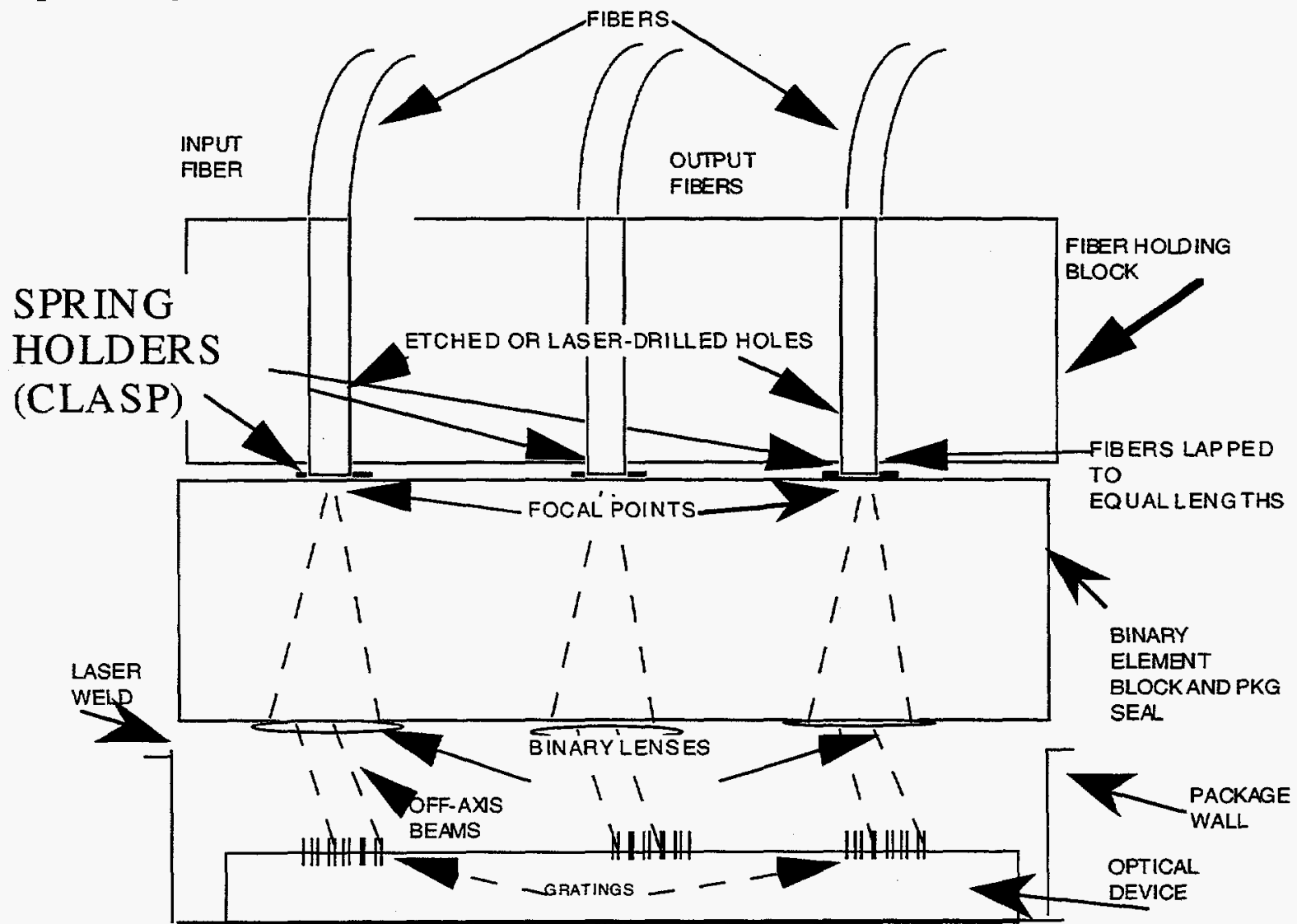

Figure 1 A schematic for a hermetic optical package, showing a fiber alignment and capture device.

This work provides a method of passive mechanical alignment of an array of single mode fibers. The technique uses a micro-machined metal spring, which captures a vertical, prepositioned fiber, moves it into accurate alignment, and holds it for attachment. The spring is fabricated from electroplated nickel, using photodefined polyimide as a plating mask. The nickel is plated about $80 \mu \mathrm{m}$ thick, so that a large fiber depth is captured. (Fig. 2) 


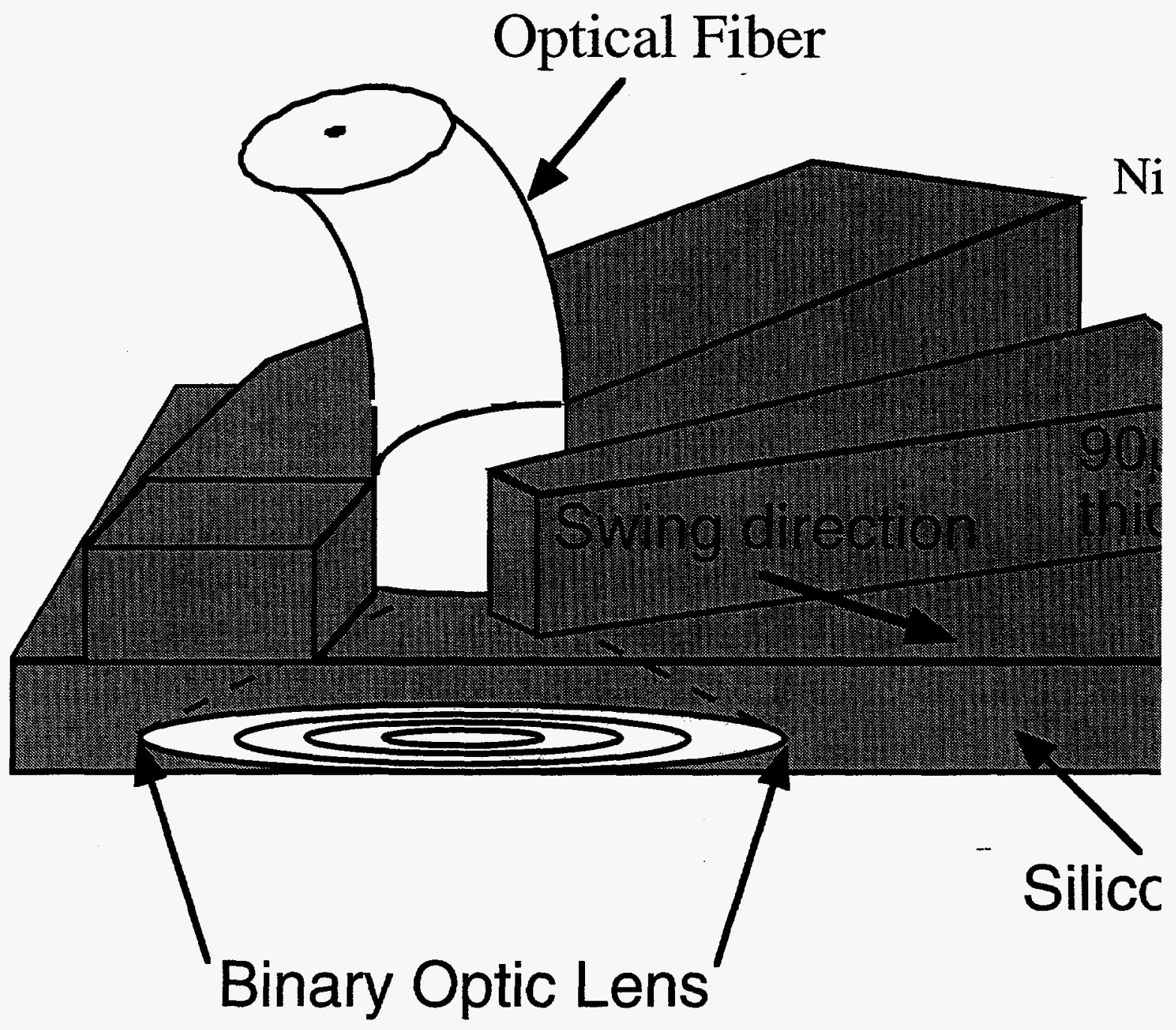

Figure 2 A micromachine designed to align and capture a single-mode optical fiber-CLASP.

In this application, the nickel springs are aligned to binary optics on the back side of the substrate. This entire concept is referred to as CLASP (Capture and Locking Alignment Spring Positioner).[2] These springs can be used for general alignment and capture of any fiber to any optical input or output device.

It is important to point out that in this application, optical fibers do not penetrate through the package wall. Instead, fibers are accurately aligned to a window, which only need be transparent to the wavelengths selected, but can be conventionally sealed. 


\section{Design}

A. Design of the CLASP locking spring Positioner. There are several elements to the design of the CLASP locking spring Positioner: (1) the spring thickness and capture depth; (2) the spring force; (3) the spring deflection; (4) the design of the capture pocket; and (5), the spacing of the CLASP positioners.

(1) The spring thickness is important to the ability to firmly guide the fiber into place and to maintain a positive lock on it when it is in final position. $80 \mu \mathrm{m}$ has been chosen as the spring thickness because it allows for good definition of the pocket shape, while maintaining more than a $50 \%$ ratio of the fiber diameter to the fiber held by the spring. The fiber is set about $75 \mu \mathrm{m}$ below the surface of the spring and is not seated against the bottom surface. If the fiber is fully seated against the substrate, too much friction is observed during sliding, with the possibility of damage to the cleaved fiber. This dimension $(75 \mu \mathrm{m})$ is defined as the capture depth.

(2) The spring force has been set so that there is sufficient force to allow the fiber to slide smoothly toward capture and be locked in place with sufficient force that it does not move during a subsequent adhesive application. A second limit to spring force is to not cause fiber damage such as chipping or cracking when the fiber is clamped in place.

In the first trial of this device, a spring force around $0.1 \mathrm{~N}$ was assumed as nominal. A series of springs were designed around this nominal value. Even the weakest of these springs could occasionally cause chipping or cracking damage to single-mode fibers. A second iteration of springs were designed around a nominal value of $0.02 \mathrm{~N}$. The spring force design data is shown in Fig. 3. The value assumed for Young's modulus of electroplated nickel is $2.1 \times 10^{-11} \mathrm{~N} / \mathrm{m}^{2}$.

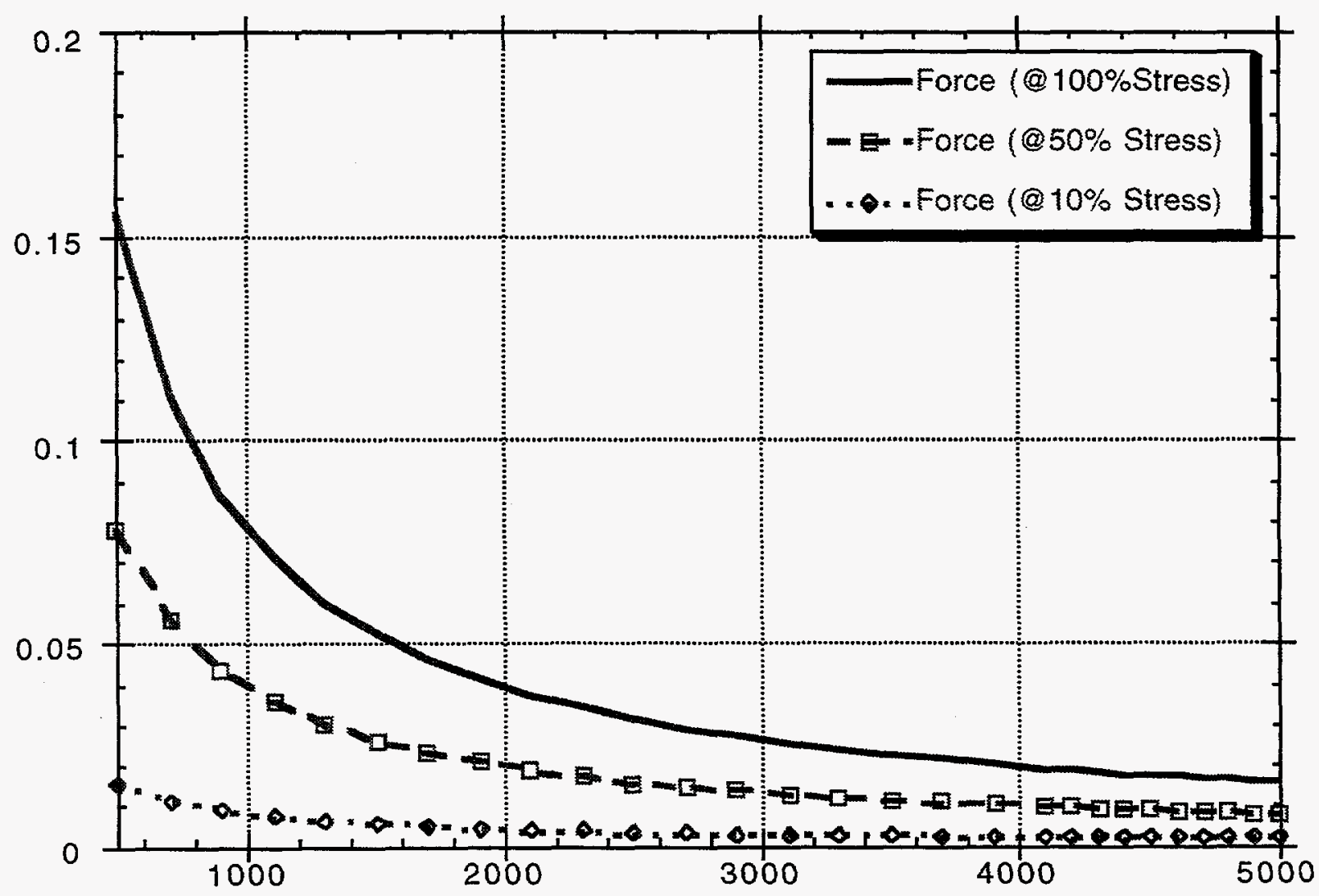

Figure 3 Spring Force versus spring lengtyh for a tapered leaf spring. 
(3) The spring elastic limits are of concern during spring tensioning. As the fiber proceeds to the capture pocket, the spring is gradually tensioned. It reaches maximum tension just before it enters the capture pocket. When it is in the pocket, tension is somewhat reduced. It is important that the spring not deform during the capture operation, because locking will not properly occur. Fig. 4 shows spring deflection as a function of length, assuming an $80 \mu \mathrm{m}$ thickness. Our current design ( $10 \%$ stress) is well within the elastic limits of nickel. .

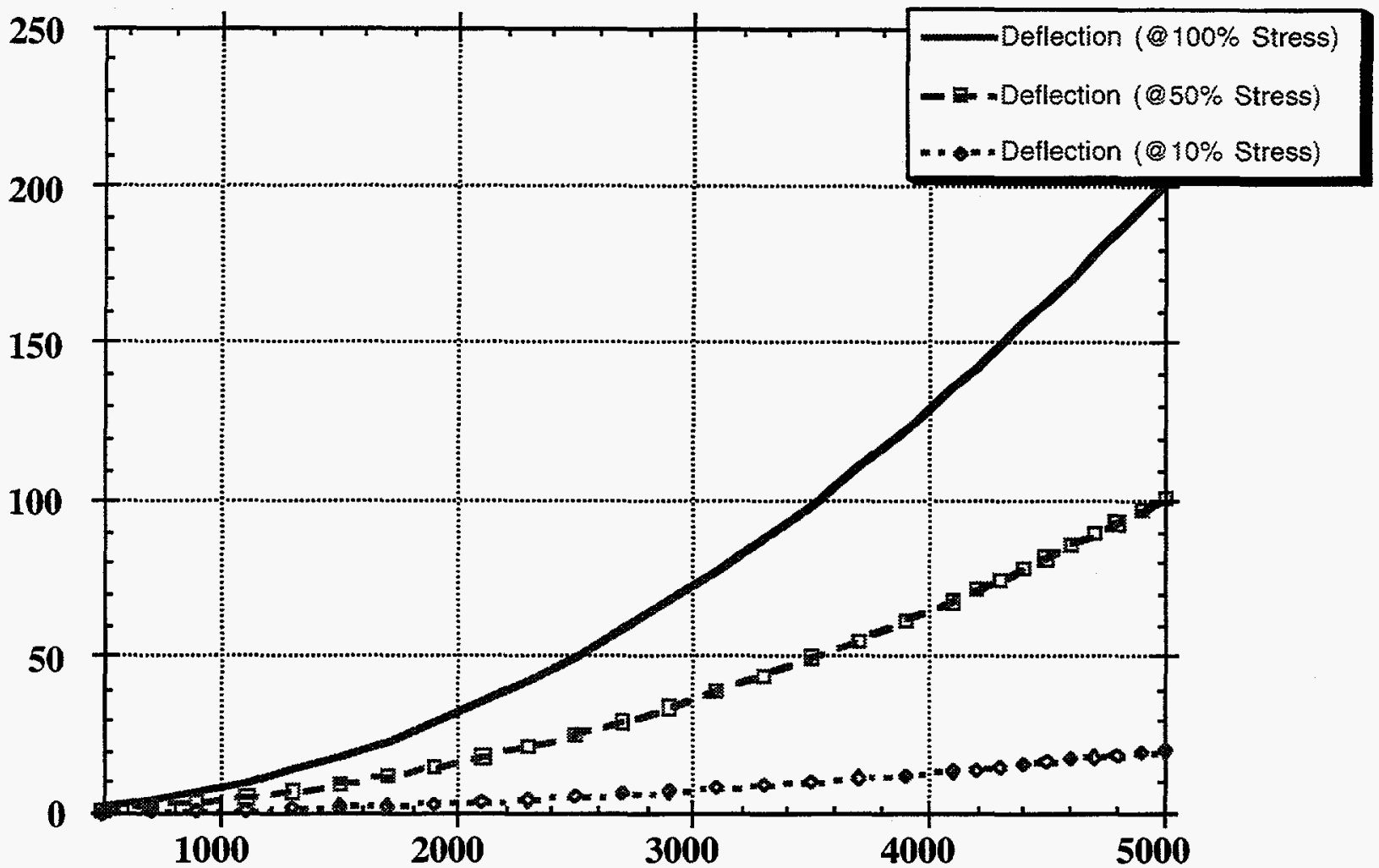

Figure 4 Spring deflection versus spring length for a tapered leaf spring.

(4) The design of the capture pocket controls the way the fiber enters the pocket and how accurately e pocket registers to other pockets or to backside features. The original concept for CLASP used round pockets. The pocket size was designed to be $1 \mu \mathrm{m}$ larger in diameter than the fiber size. This approach requires very accurate process control of the patterning and plating process. The round pocket concept has been tested, with several different compensations for the patterning and plating processes. Three different compensations from the nominal fiber size of 125 $\mu \mathrm{m}$ have been tried These process compensations are needed to accommodate the change of the nickel feature size during patterning and plating. The three compensation sizes are $+7,+14$, and $+21 \mu \mathrm{m}$. Other pocket designs include square or vee-shaped pockets. See Fig. $5 \mathrm{a}, \mathrm{b}$, and $c .$. The vee-shaped pockets allow for greater process variation or fiber size. The assumption is that all adjacent pockets will have the same process variation. 


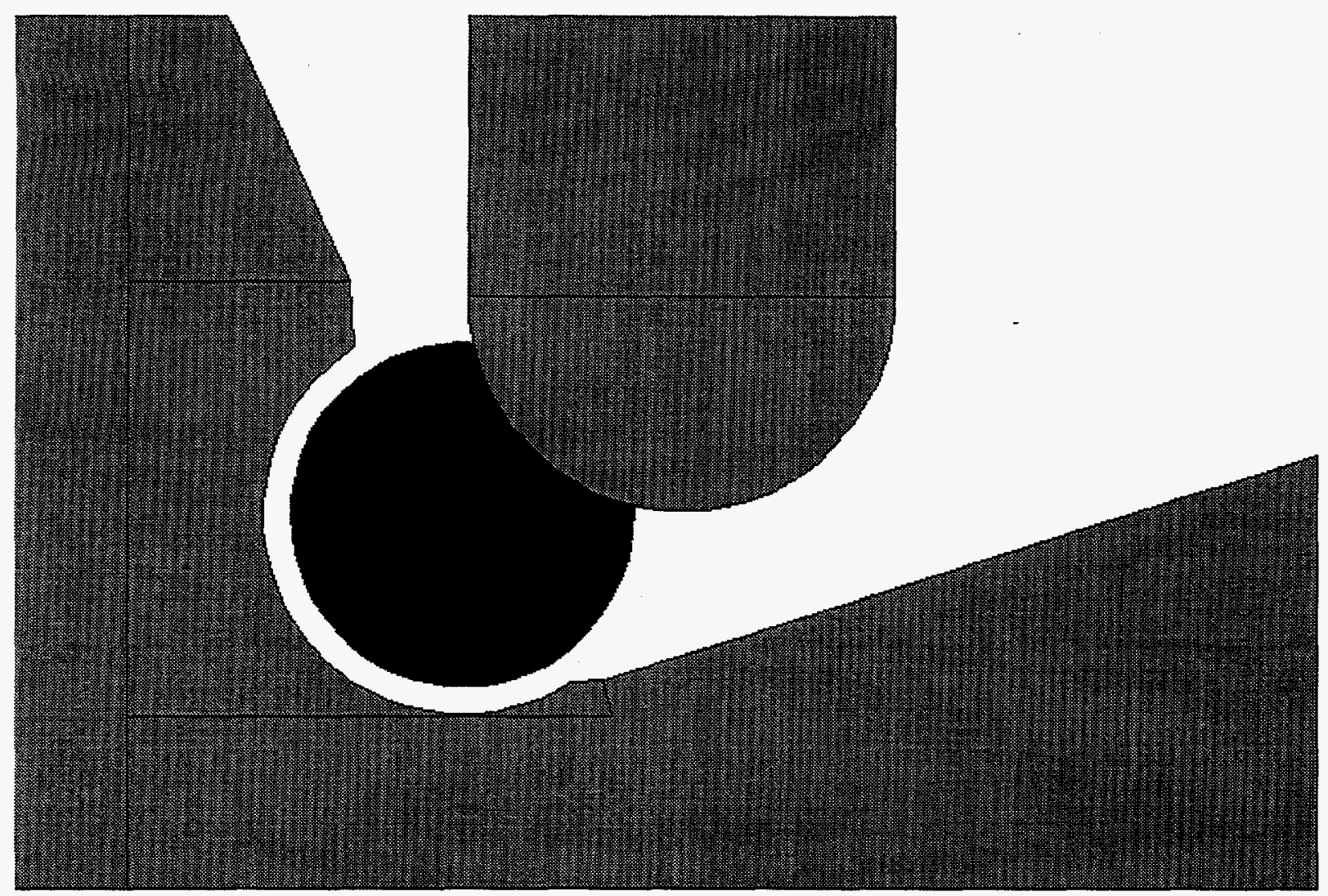

(a)

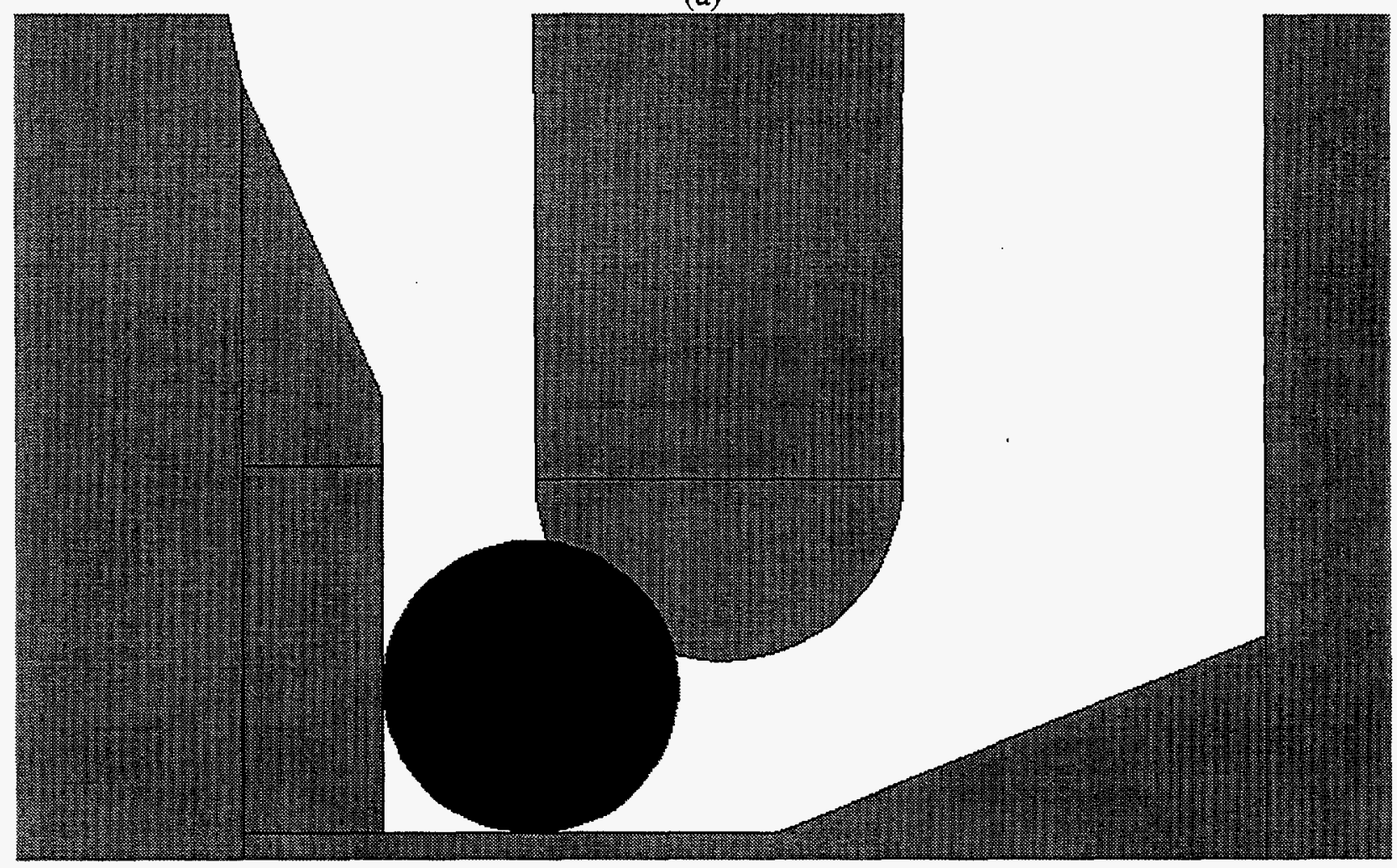

(b) 


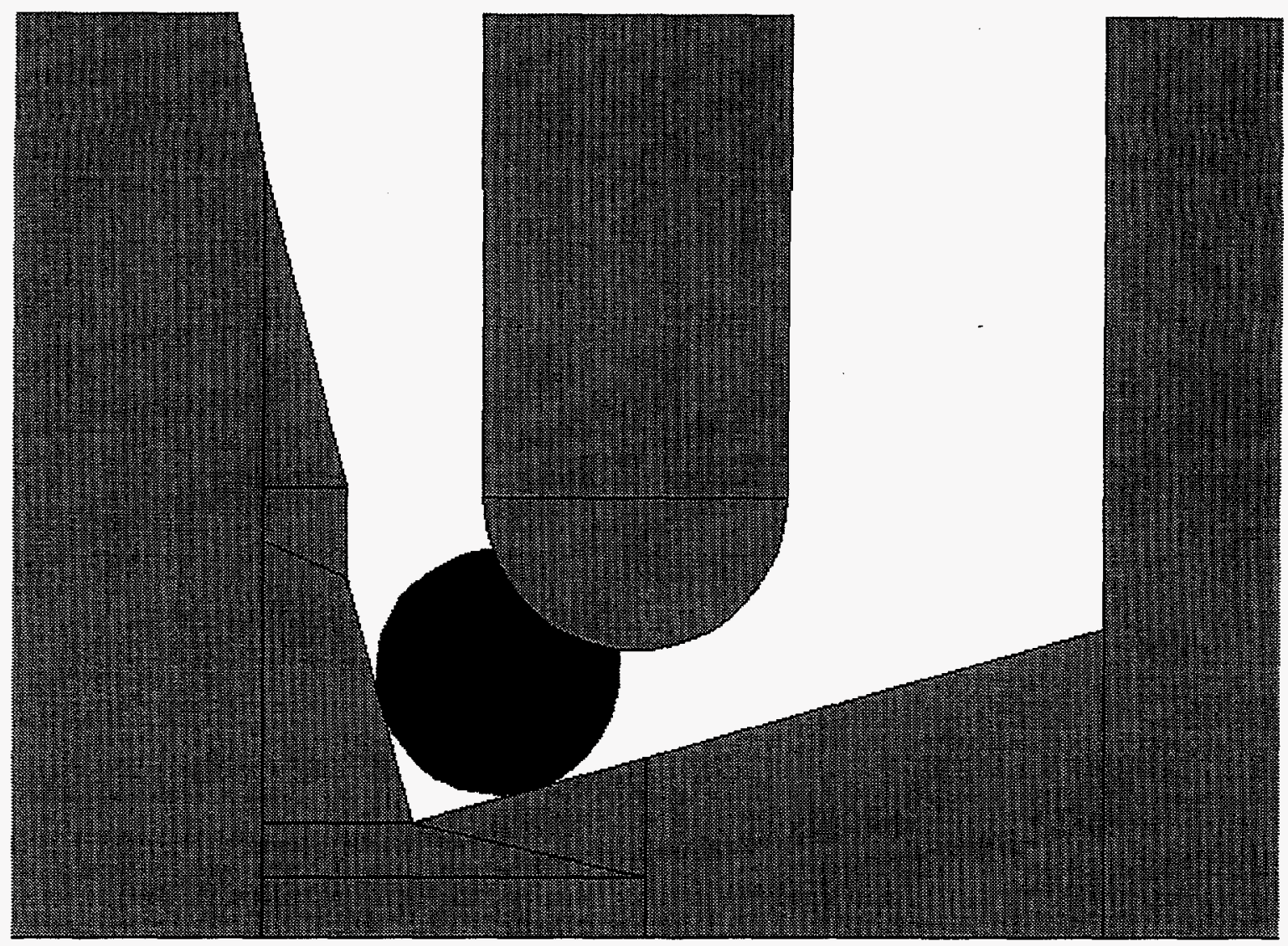

(c)

Figure 5 (a) Round-pocket CLASP design; (b) Square-pocket CLASP design; (c) V-pocket CLASP design;

(5) The spacing of the CLASP positioners is limited by the fiber diameters, not by the positioners. It is possible to imagine an arrangement of positioners that are as close as $50 \mu \mathrm{m}$ greater than the fiber diameters. In our current demonstration, we have chosen to array four single-mode $125 \mu \mathrm{m}$ fibers in a linear arrangement. We have set the fiber cores $750 \mu \mathrm{m}$ apart. See Fig. 6. 


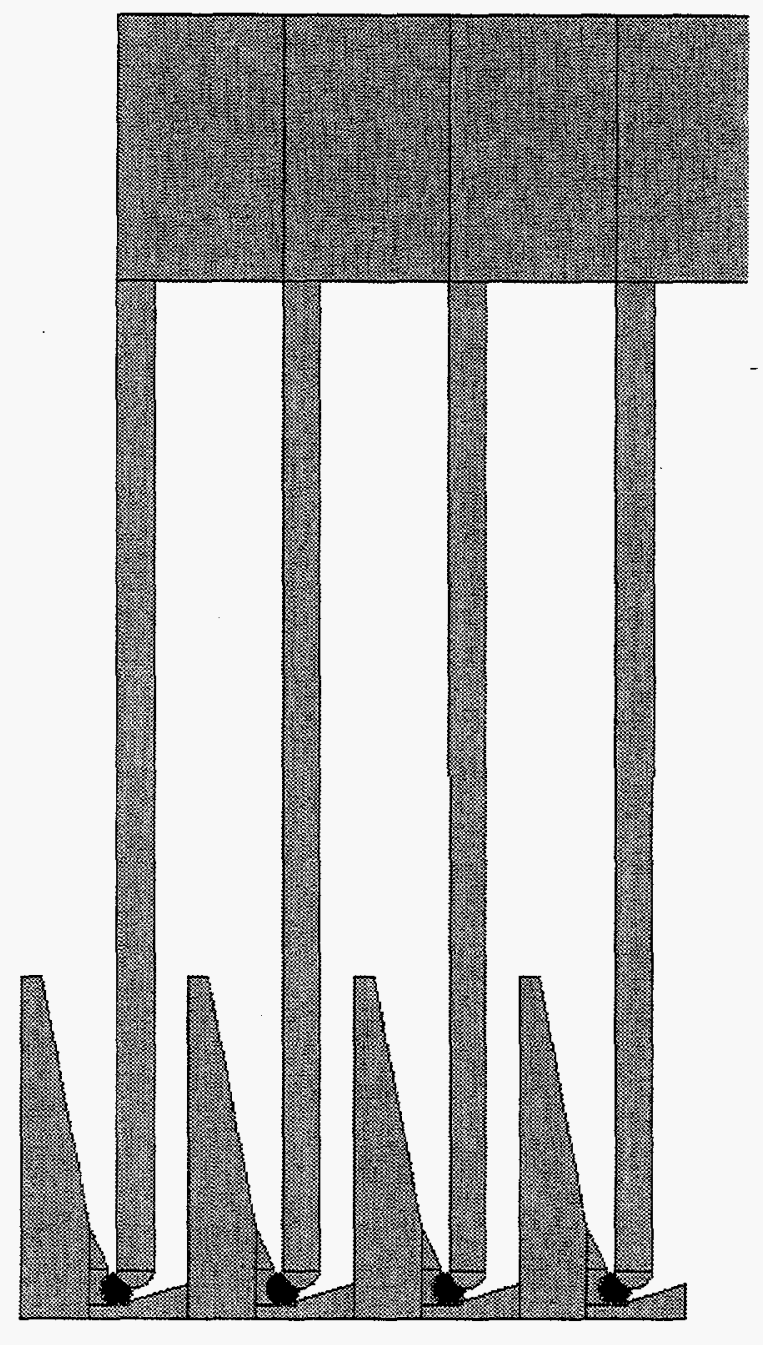

Figure 6 Alinear four-pocket design at $750 \mu \mathrm{m}$ spacing.

B. Design of the pre-positioning block. The fibers are pre-positioned in a separate silicon block, which has been laser-drilled to accept optical fiber. This block provides several functions: (1) a holder for coarse alignment pins used to roughly position the fibers in the CLASP funnel, so that the capture procedure can start; (2) a holder for setting the fibers to equal length; and (3) a means of attachment of the fiber block to the binary optic block after alignment.

1. Rough positioning of fibers in a block requires drilling holes in a block of silicon. The holes should be smooth, free of debris, perpendicular to the block, at the correct step distance, and be $2 \mu \mathrm{m}$ larger than the optical fibers. The first attempt at meeting these criteria used a doubled YAG laser. This laser melted its way through the silicon, producing holes which vary in diameter as the hole proceeds through the silicon. In order to insure a hole at least $127 \mu \mathrm{m}$ in diameter at the exit, a starting hole of $165 \mu \mathrm{m}$ was required. In addition, lack of perpendicularity caused the exit holes to be the incorrect step distance.

These problems were corrected with the use of a excimer laser, which ablates the holes. This system has been able to maintain hole diameter at $127 \mu \mathrm{m}$ and produce perpendicular holes. Coarse alignment pins, with a $1 \mathrm{~mm}$ diameter, are inserted through laser drilled holes in the silicon block and are pushed against a stop to protrude $2 \mathrm{~mm}$.

2. The fibers are then inserted in the silicon block and are pushed against the same stop until they protrude $2 \mathrm{~mm}$. The fibers are then backed away $5 \mu \mathrm{m}$ from the stop. This procedure sets the alignment pins as positive stops and prevents the fibers from dragging on the CLASP spring surface, since they are recessed by $5 \mu \mathrm{m}$, which makes them equal length. 
3. When the fibers are eventually aligned and captured by CLASP, final attachment of the pre-positioning block and the CLASP springs must occur. Since the fibers aren't strong enough to bear any weight, the attaching surfaces are the coarse alignment pins and the U-shaped features that act as pin stops. The pins provide the support for this sandwich and act as surfaces for adhesive joining with the pin stops. See Fig. 7

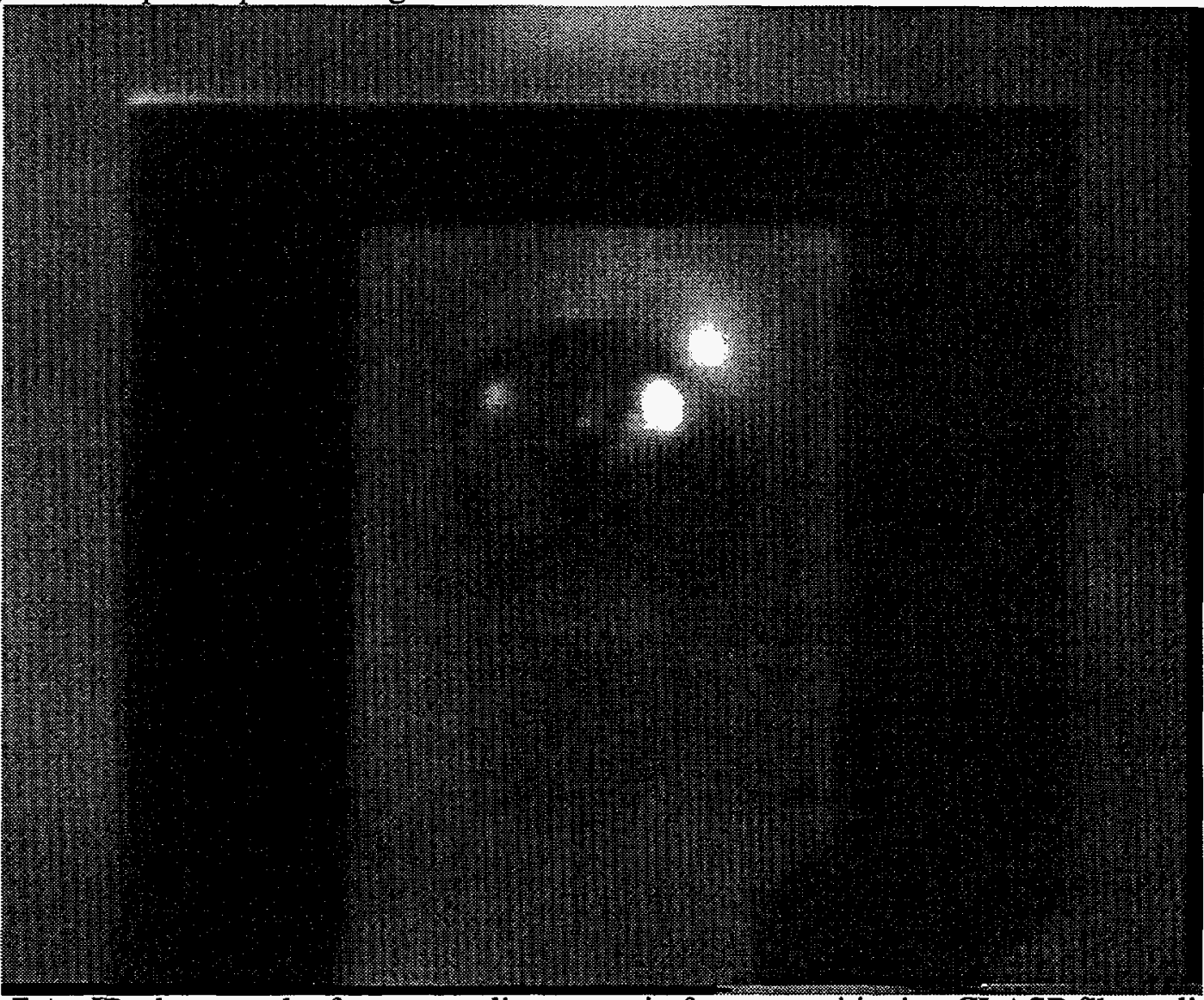

Figure 7 An IR photograph of a coarse-alignment pin for pre-positioning CLASP fiber alignment as it approaches the U-shaped pin stop.

C. Back side alignment If CLASP is to be used with other features, such as lenses, on the opposite side of the substrate from the CLASP springs, accurate alignment through the substrate is required. Infra-red techniques through the wafer are usually not accurate enough. A better technique is to use a double-sided aligner, placing alignment marks simultaneously on both sides of the wafer. Both patterns can be later aligned to these marks.

\section{Fabrication of CLASP}

The fabrication process has three basic steps: (1) patterning; (2) electroplating; and (3) freeing the moving parts from the substrate. This process is similar to that of Allen, et al [2]

1. Undoped silicon wafers $250 \mu \mathrm{m}$ thick are used as substrates. It is important that wafers be undoped so that there is maximum transmission at $1300 \mathrm{~nm}$, the intended use wavelength. An electroplating seed and release layer of titanium and gold, is evaporated, with layer thicknesses of $50 \mathrm{~nm}$, and $100 \mathrm{~nm}$ respectively.

2. Photodefinable polyimide (DuPont 2721) is spun on using multiple coats, with $105^{\circ} \mathrm{C}$. bakes after each coat. Total polyimide thickness is $85 \mu \mathrm{m}$. The polyimide is exposed with an MJB3 (Suss) contact printer. After spray development and an oxygen plasma descum, the pattern is electroplated in Lectro-Nic plating solution from Ethone-Omi Corp. The polyimide is removed with n-methyl pyrolidone, followed by an oxygen plasma descum.

3. The gold is removed by argon sputter; and the bottom spring release etch is performed in buffered oxide etch A completed spring is shown in Fig. 8. 


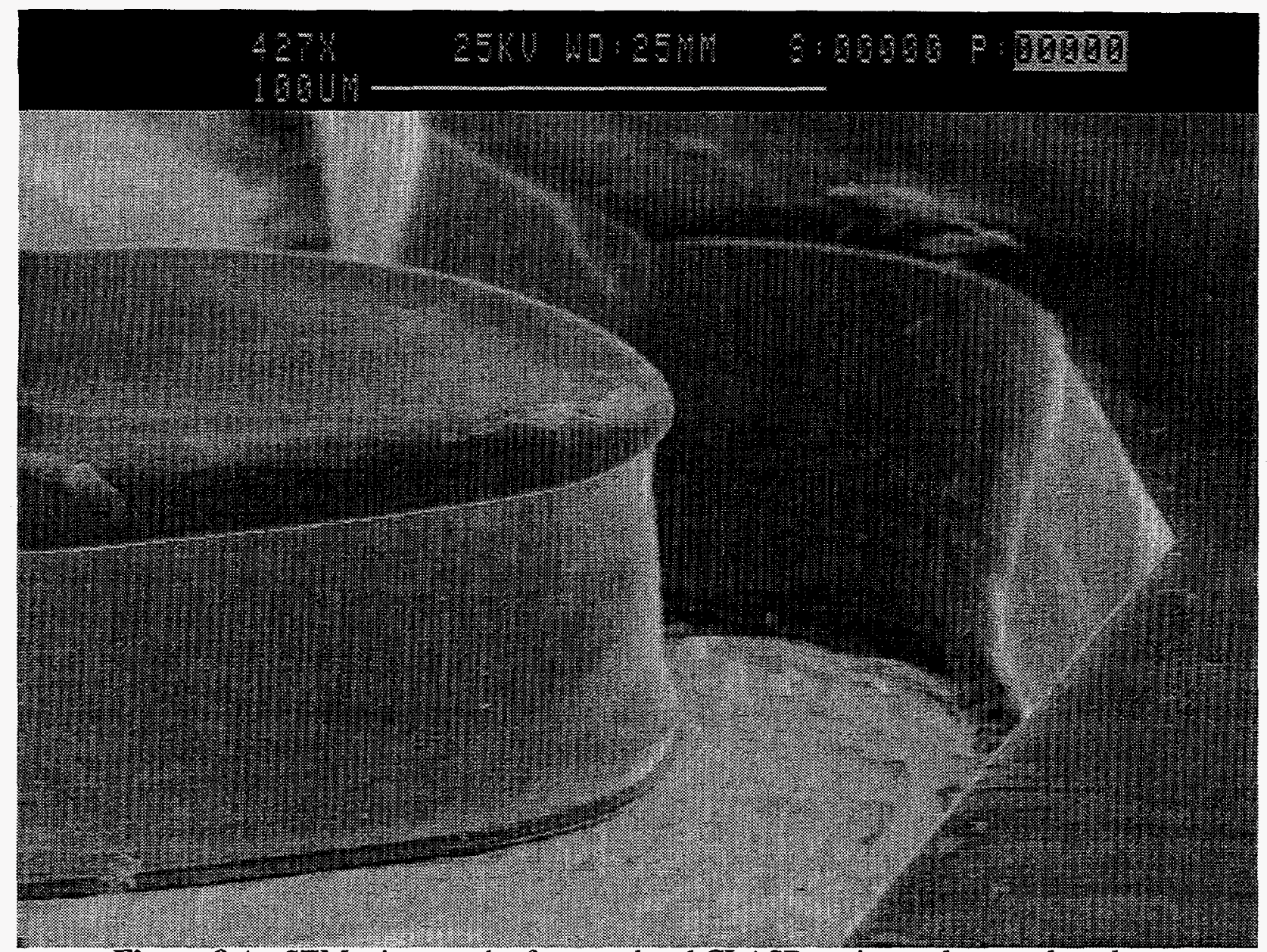

Figure 8 An SEM micrograph of a completed CLASP spring and a round-pocket.

Experimental Techniques for Measurement of CLASP

After the pre-positioning block and the CLASP block have been fabricated, the two blocks must be positioned and joined. The method used for alignment involves moving the block holding the pre-positioned fibers, (which have been adjusted to equal lengths), against the micromachined spring /binary lens (CLASP) block. This movement allows the flexible, individual fibers to lock into place in their respective micromachined springs. Since these springs have been previously aligned to binary optics residing on the back of the substrate, a total alignment of fiber to binary optics is now accomplished.

In order to confirm that the fibers have been accurately positioned, a method was designed to observe alignment and capture, as well as to measure the accuracy of fiber core placement of the four CLASPed fibers. See Fig. 9. An infra-red camera was positioned at the backside of the CLASP fiber block. A $1300 \mathrm{~nm}$ laser was used to illuminate the backside of the pre-positioning block. Since silicon is transparent to $1300 \mathrm{~nm}$ radiation, an image is formed which shows the nickel features in silhouette. If $1300 \mathrm{~nm}$ light is also sent through the single-mode fibers, then the cores of these fibers are brightly illuminated. 


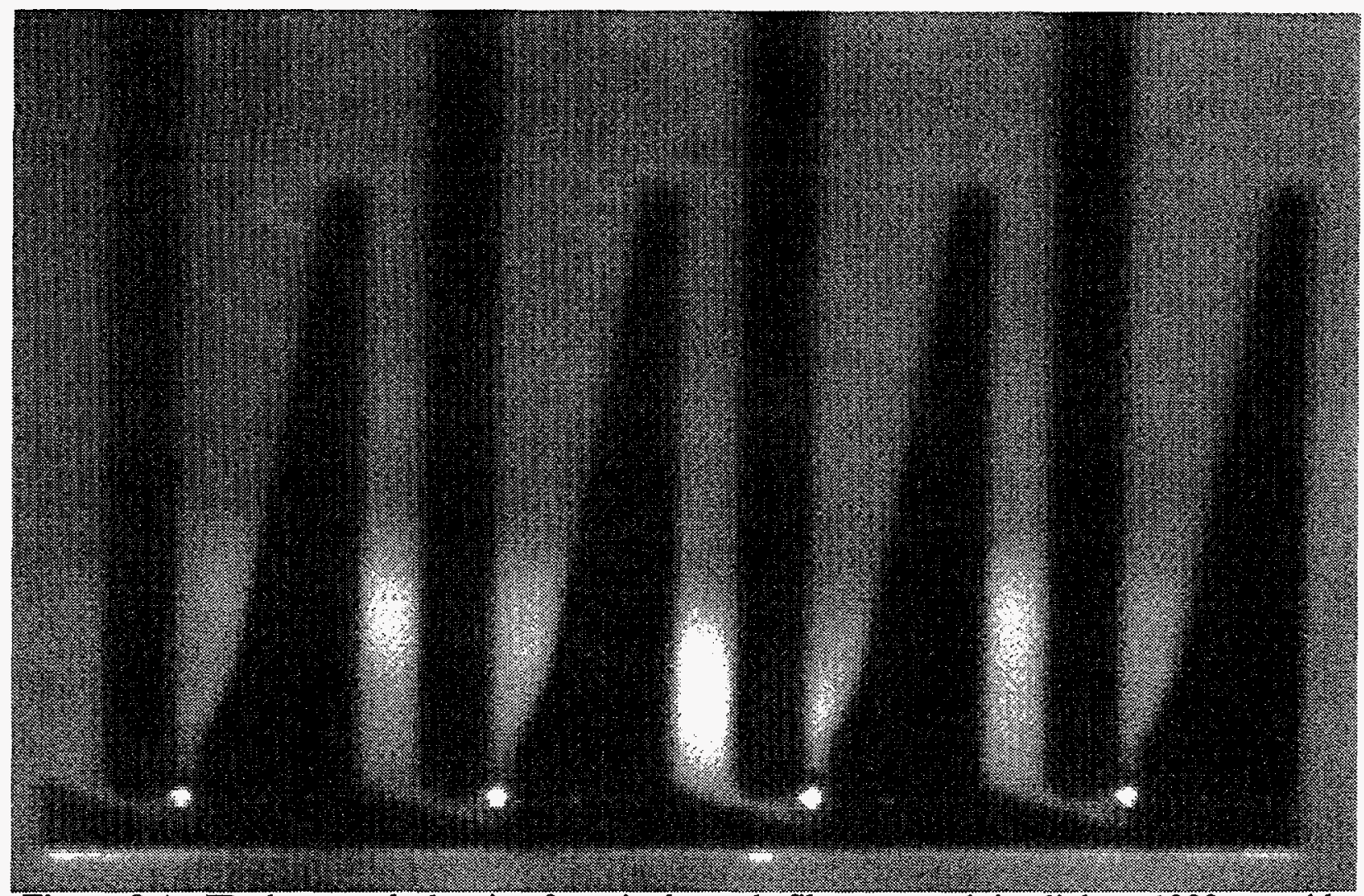

Figure 9 An IR photograph showing four single-mode fibers transmitting light at $1300 \mathrm{~nm}$, with the CLASP structure in silhouette.

It is possible to make accurate measurements of the distance between illuminated optical fiber cores, using an optical microscope, an infra-red sensitive camera, and precision stepping motors.

This technique involves measuring the distance between optical fiber cores at high magnification. (60x). See Fig. 10. The microscope cross-hair is positioned on the first of four fiber cores, that have been aligned by CLASP. This point serves as the zero reference. The stepping motors are then moved to align on the next core. The stepping motor accuracy is claimed to be $0.1 \mu \mathrm{m}$. This measurement is repeated for all three of the cores. 


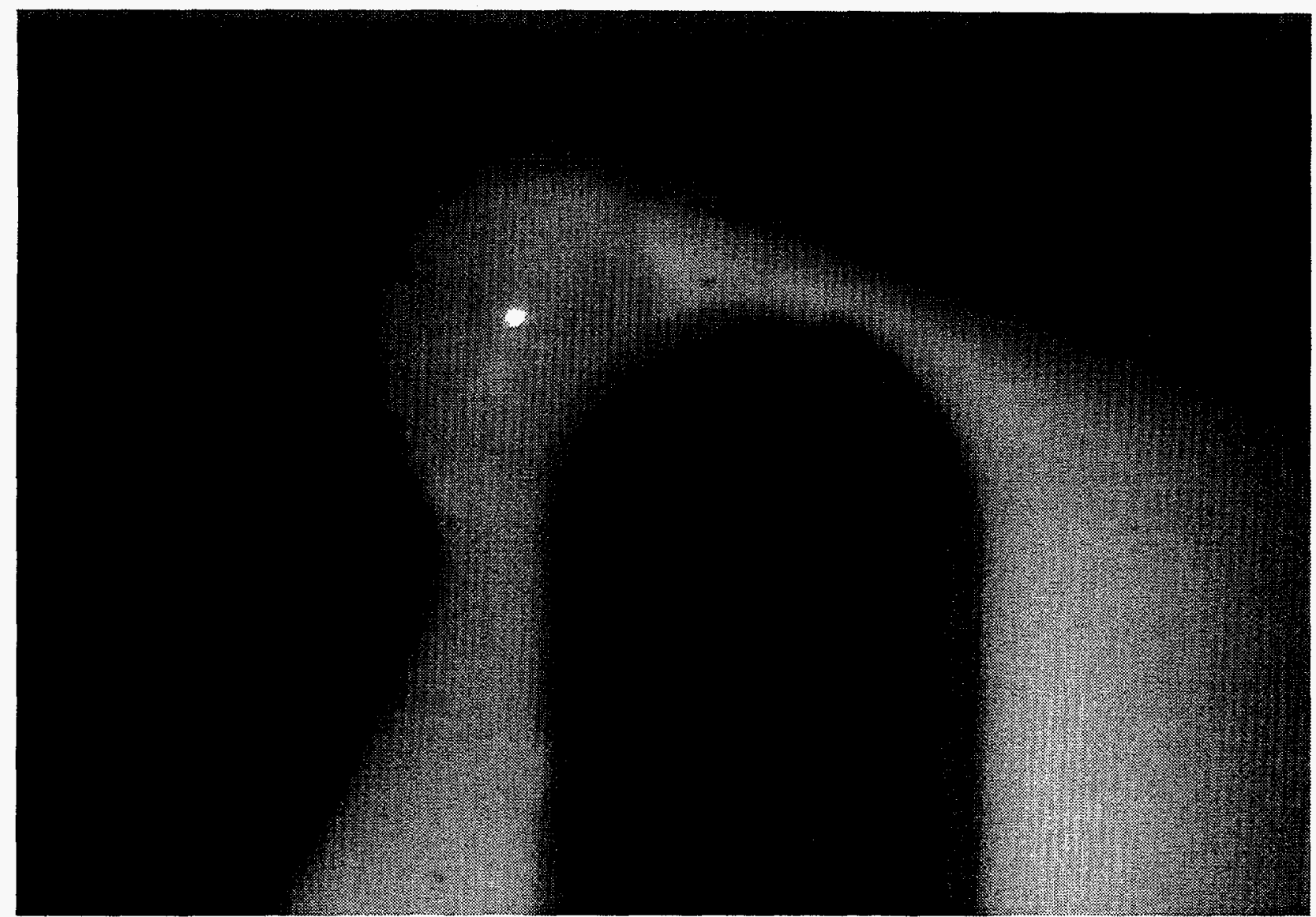

Figure 10 An IR photograph showing a 60x captured fiber in a round-pocket.

\section{Experimental Results}

Measurements have been made on different size compensations of the circular pockets, as well as on the square and vee-shaped pockets. The results are shown in Fig. 11. Based on somewhat limited data, it would appear that $+21 \mu \mathrm{m}$ round pockets, square, and vee shaped pockets have alignment tolerances around $2 \mu \mathrm{m}$ on average. 


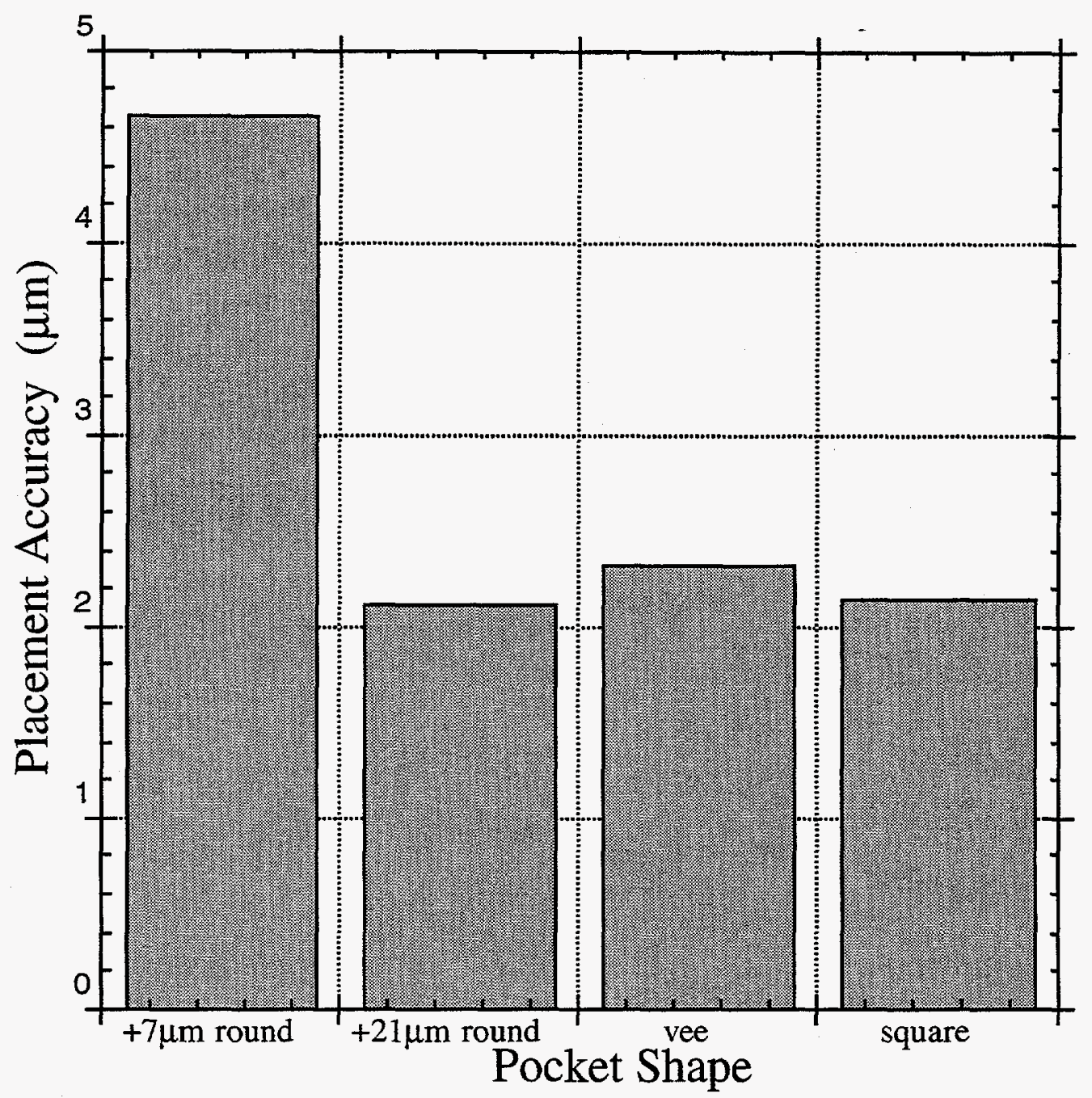

Figure 11 A graph showing the placement accuracy of different pocket shapes.

The variation in alignment is probably caused by non-vertical plated sidewalls. This non-vertical profile is traced to the polyimide masking material. Thick photoresist masking material has been investigated which has much more vertical sidewalls. This should improve the accuracy of capture. AZ4903 positive photoresist was spun and patterned about $50 \mu \mathrm{m}$ thick. Nickel was electroplated to this thickness, with very straight profiles compared to those made with polyimide. Figure 12 and Figure 13 show these straight profiles. CLASP devices were made and tested as previously described, using positive photoresist in place of polyimide. However, the only trial did not produce any difference in accuracy from the prjevious data. 


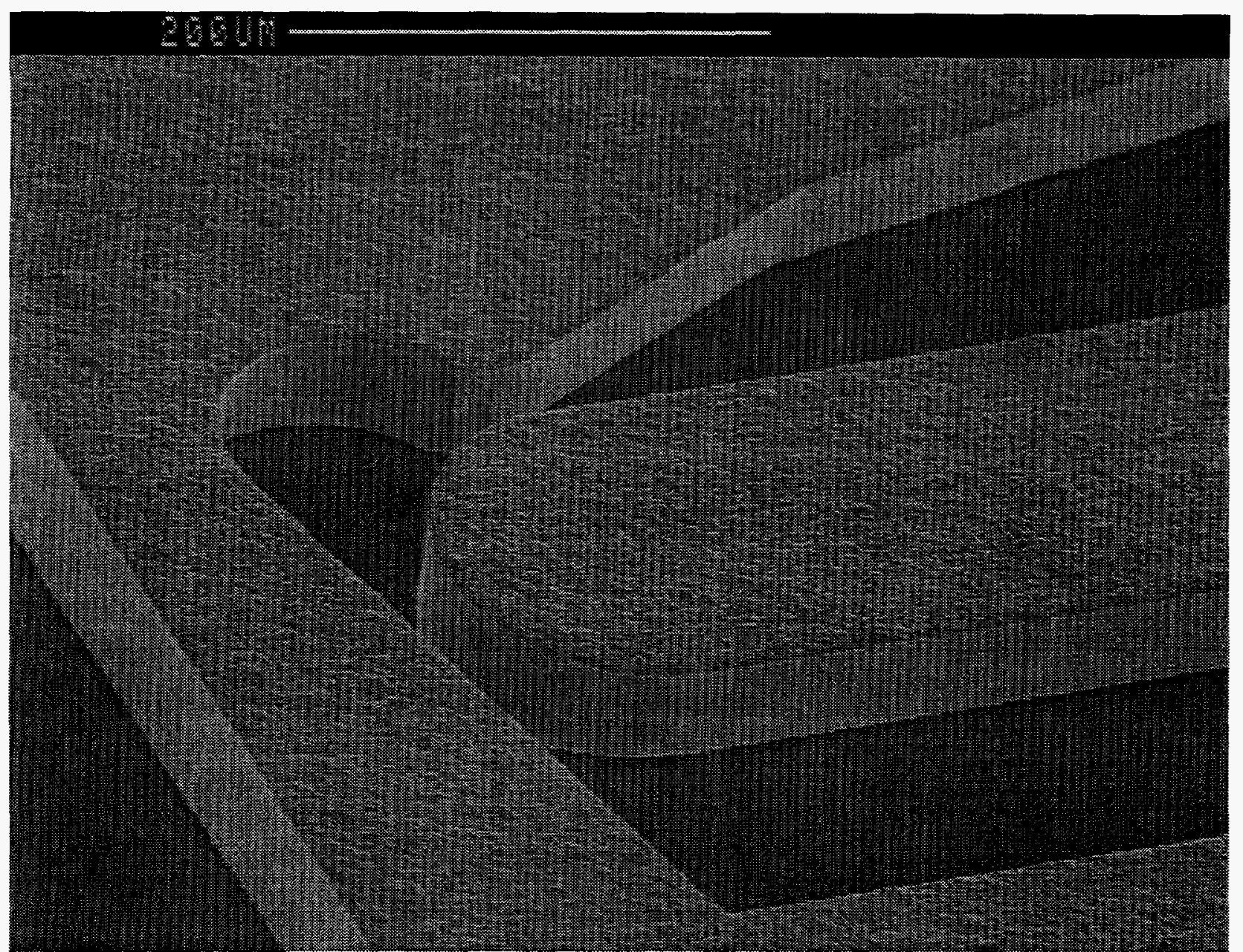

Figure 12 A SEM micrograph of a completed CLASP spring and round pocket made by using thick positive photoresist in place of polyimide. 


\section{BDUR}

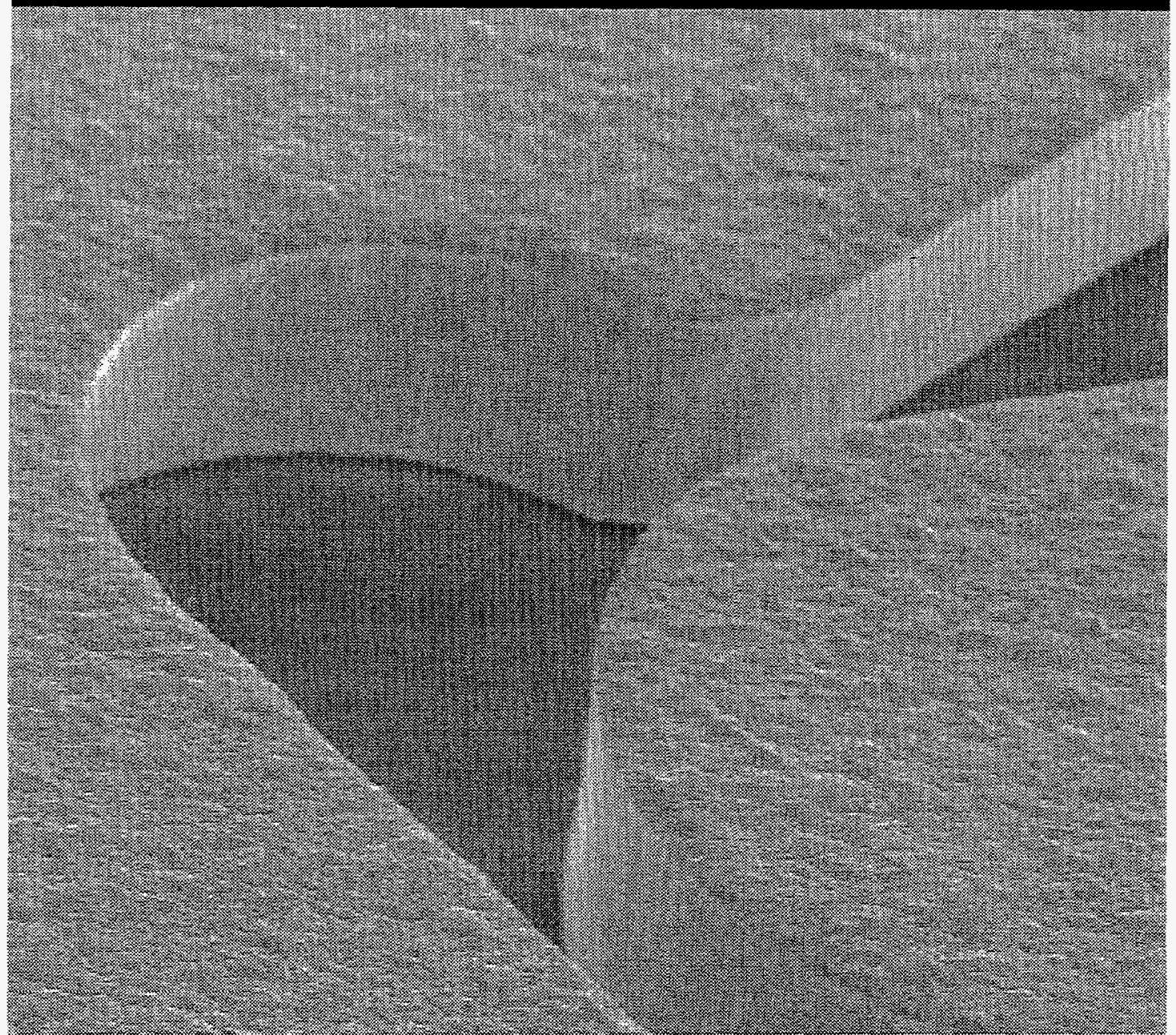

Figure 13 A SEM micrograph showing a close-up of the vertical walls of a CLASP spring and round pocket made by using thick positive photoresist.

\section{Conclusion}

A new concept for aligning and capturing single-mode fibers has been shown. This concept is called CLASP. Accurate alignment $(\sim 2 \mu \mathrm{m})$ of four-fiber arrays has been demonstrated.

\section{References:}

1. S. H Kravitz, G. R. Hadley, M. E. Warren, J. R. Wendt, G. A. Vawter, J. C. Word, R. F. Corless, R. F. Carson, M.G. Armendariz, B. E. Hammons, R.E. Leibenguth " Waveguide-toFiber Coupling Using a Second-Order Grating and an Anamorphic Binary Optic", presented at LEOS93, San Jose, CA,. November 15-18, 1993, p 472-3

2. S. H Kravitz, J.C. Word, M. B. Snipes, M.G. Armendariz, P. K. Seigal, C. T. Sullivan, "A Passive Micromachined Device for Alignment of Arrays of Single-mode Fibers for Manufacturable Photonic Packaging, "presented at LEOS94, Boston MA, October 31-November 3, 1994, p 226-7

3. A. B. Frazier, M. G. Allen, "High Aspect Ratio Electroplated Microstructures Using A Photosensitive Polyimide Process" Micro Electro Mechanical Systems '92, Travemunde (Germany), February 4-7, 1992 


\section{DISTRIBUTION:}

$\begin{array}{llll}1 & \text { MS0320 } & 1010 & \text { LDRD Office } \\ 1 & \text { MS0603 } & 1313 & \text { T. E. Zipperian } \\ 1 & \text { MS0603 } & 1314 & \text { P. Esherick } \\ 1 & \text { MS0603 } & 1312 & \text { M. E. Warren } \\ 10 & \text { MS0874 } & 1342 & \text { M. G. Armendariz } \\ 10 & \text { MS0603 } & 1313 & \text { S. H. Kravitz } \\ 1 & \text { MS1082 } & 1333 & \text { D. W. Palmer } \\ 1 & \text { MS1080 } & 1325 & \text { P. J. McWhorter } \\ 1 & \text { MS1080 } & 1325 & \text { J. J. Sniegowski } \\ 1 & \text { MS1425 } & 1307 & \text { M. W. Scott } \\ 1 & \text { MS0603 } & 1312 & \text { A. Owyoung } \\ 1 & \text { MS1425 } & 1315 & \text { S. J. Martin } \\ 1 & \text { MS1425 } & 1315 & \text { G. C. Frye } \\ 1 & \text { MS1425 } & 1315 & \text { W. K. Schubert } \\ 1 & & & \\ \text { Files } & \text { MS9018 } & 8940-2 & \text { Central Technical } \\ 5 & & & \\ 2 & \text { MS0899 } & 4414 & \text { Technical Library } \\ & 0617 & 12690 & \text { Review \& Approval } \\ & & & \text { Desk for DOE/OSTI }\end{array}$

